\title{
Pelatihan Penggunaan Pupuk Organik Cair (POC) Sebagai Alternatif Pengganti Larutan Nutrisi AB Mix pada Pertanian Sistem Hidroponik di BON Farm Narmada
}

\author{
M. Liwa Ilhamdi ${ }^{1 *}$, Khairuddin ${ }^{1}$, Muh. Zubair ${ }^{2}$ \\ ${ }^{I}$ Program Studi Pendidikan Biologi, FKIP Universitas Mataram, Mataram, Indonesia \\ ${ }^{2}$ Program Studi PPKn, FKIP Universitas Mataram, Mataram, Indonesia
}

DOI: https://doi.org/10.29303/jpmsi.v2i1.20

Citation: Ilhamdi, M. L., Khairuddin, Zubair, M. 2020. Pelatihan Penggunaan Pupuk Organik Cair (POC) Sebagai Alternatif Pengganti Larutan Nutrisi AB Mix pada Pertanian Sistem Hidroponik di BON Farm Narmada. Jurnal Pengabdian Masyarakat Sains Indonesia (JPMSI). 2(1): 40-44.

\section{Article history}

Received: November $15^{\text {th }} 2019$

Revised: December $20^{\text {th }} 2019$

Accepted: December $31^{\text {th }} 2019$

*Corresponding Author: M.

Liwa Ilhamdi, FKIP

Universitas Mataram, Mataram,

Indonesia;

Email:

liwa_ilhamdi@unram.ac.id

\begin{abstract}
Abstrak: Sistem hidroponik merupakan salah satu teknologi bercocok tanam dengan menggunakan media tanam air, nutrisi dan oksigen tanpa menggunakan tanah sebagai media tumbuhnya. Faktor nutrisi adalah penentu keberhasilan dalam bercocok tanam sistem hidroponik. Nutrisi yang dibutuhkan untuk mendukung pertumbuhan tanaman diperoleh melalui pemberian larutan yang mengandung unsur makro dan mikro. Larutan nutrisi yang biasa digunakan oleh petani adalah larutan AB Mix. Mahalnya harga pupuk $\mathrm{AB}$ Mix memperbesar biaya produksi, sehingga dibutuhkan inovasi sebagai alternatif pengganti nutrisi untuk tanaman hidroponik. Pupuk Organik Cair (POC) merupakan salah satu alternatif yang ditawarkan untuk memecahkan permasalahan tersebut. POC mengandung komposisi nutrisi yang dibutuhkan oleh tanaman seperti halnya pupuk AB Mix, namun bisa diperoleh dengan harga yang sangat murah karena berasal dari fermentasi bahan organik. Pelatihan Penerapan POC ini akan dilakukan di BON Farm Narmada. Tujuan dilakukannya kegiatan pengabdian ini adalah untuk (1) Meningkatkan pengetahuan masyarakat tentang teknik pertanian hidroponik, (2) Mengimplementasikan penggunaan Pupuk Organik Cair (POC) sebagai alternatif pengganti pupuk AB Mix pada pertanaian hidroponik. Kegiatan pengabdian ini akan dilakukan dalam bentuk penyampaian teori, pelatihan dan pendampingan praktek yang disampaikan oleh tim pengabdian dan diikuti oleh Kelompok Pemuda Mandiri BON Farm Narmada, Lombok Barat. Pada akhir kegiatan pengabdian diharapkan masyarakat mempunyai pengetahuan dan keterampilan dalam bertani sistem hidroponik dan menggunakan POC sebagai alternatif pengganti pupuk AB Mix.
\end{abstract}

Kata kunci: Pelatihan, Hidroponik, Nutrisi, POC, AB Mix

\section{Pendahuluan}

Seiring dengan pertumbuhan jumlah penduduk berdampak pada peningkatan kebutuhan bahan pangan namun terjadi penurunan pada luas lahan yang digunakan sebagai tempat menanam bahan pangan. Salah satu jenis kebutuhan bahan pangan bagi masyarakat adalah sayuran. Sayuran dibutuhkan sebagai pelengkap nutrisi (sumber serat dan vitamin) yang dibutuhkan oleh tubuh. Budidaya dilahan terbatas atau pekarangan menjadi alternatif solusi untuk memecahkan permasalah lahan yang semakin menyempit untuk pemenuhan kebutuhan nutrisi rumah tangga. Selain sistem bercocok tanam secara konvensional, salah satu sistem yang bisa diterapkan dalam pertanian di lahan terbatas adalah hidroponik.

Sistem hidroponik merupakan salah satu teknologi bercocok tanam dengan menggunakan media tanam air, nutrisi dan oksigen tanpa menggunakan tanah sebagai media tumbuhnya. Saat ini terdapat enam jenis sistem penanaman secara hidroponik, yaitu sistem sumbu (Wick), sistem kultur air, sistem pasang surut, sistem irigasi tetes, sistem NFT dan sistem aerponik (Krisnawati, 2014).

BON Farm Narmada merupakan salah satu Kelompok Pemuda Mandiri (KPM) yang menginisiasi pengembangan kewirausahaan 
Ilhamdi et al, Jurnal Pengabdian Masyarakat Sains Indonesia 2020, 2 (1):40-44 DOI : https://doi.org/10.29303/ipmsi.v2i1.20

khususnya dalam bidang biteknologi dan pertanian di Desa Lembuak, Kecamatan Narmada. Komoditas yang telah dikembangkan oleh kelompok ini adalah jamur tiram, ikan nila, lele, itik dan ayam kampung. Saat ini BON Farm sedang mengembagkan pertanian Hidroponik. Pertanian hidroponik yang diterapkan masih terbatas dengan sistem wick. Sistem wick adalah sistem yang paling sederhana dalam pertanian hidroponik. Belum ada inovasi yang ditambahkan dalam sistem ini, sumber nutrisi hanya berasal dari pupuk AB Mix.

Faktor nutrisi adalah penentu keberhasilan dalam bercocok tanam sistem hidroponik (Perwitasari, dkk, 2012). Nutrisi yang dibutuhkan untuk mendukung pertumbuhan tanaman diperoleh melalui pemberian larutan yang mengandung unsur makro dan mikro. Resh (1983) menyatakan bahwa, dalam larutan nutrisi tersebut mengandung 6 unsur makro dan unsur mikro. Unsur makro terdiri atas N, $\mathrm{P}, \mathrm{K}, \mathrm{Ca}, \mathrm{Mg}$ dan $\mathrm{S}$ sedangkan unsur mikro terdiri atas $\mathrm{Fe}, \mathrm{Cl}, \mathrm{Mn}, \mathrm{Cu}, \mathrm{Zn}, \mathrm{B}$ dan Mo. Larutan nutrisi inilah yang kemudian dikenal dengan "larutan $\mathrm{AB}$ mix". Pupuk ini dapat diperoleh di toko pertanian, namun dengan harga yang cukup mahal yaitu sekitar Rp. 30.000 - Rp. 50.000,- tergantung kualitas pupuknya.

Mahalnya harga pupuk AB Mix memperbesar biaya produksi, sehingga dibutuhkan inovasi sebagai alternatif pengganti nutrisi untuk tanaman hidroponik. Pupuk Organik Cair (POC) merupakan salah satu alternatif yang ditawarkan untuk memecahkan permasalahan tersebut. POC mengandung komposisi nutrisi yang dibutuhkan oleh tanaman seperti halnya pupuk AB Mix, namun bisa diperoleh dengan harga yang sangat murah karena berasal dari fermentasi bahan organik. Bahan organik ini bisa diperoleh dari sampah dedauanan hijau, jerami, kotoran unggas dan sejenisnya. Fitriyatno, dkk. (2012) melaporkan bahwa POC yang terbuat dari limbah pasar memberikan pengaruh nyata terhadap pertumbuhan selada hidroponik. Hal serupa juga dilaporkan oleh Hamli, dkk. (2015) bahwa penggunaan $10 \mathrm{ml} / \mathrm{L}$ POC mempengaruhi pertumbuhan dan perkembangan tanaman Sawi hidroponik.

\section{Metode}

Metode pelaksanaan kegiatan pengabdian masyarakat ini difokuskan pada upaya penyelesaian masalah yang sedang dihadapi oleh masyarakat dalam melakukan pertanian hidroponik.
e-ISSN : 2715-2537

p-ISSN : 2715-2545

Permasalahan tersebut dapat diketahui melalui pencapaian tujuan yang sudah dikemukakan sebelumnya yang terdiri dari (1) Meningkatkan pengetahuan masyarakat terkait dengan pertanian hidroponik (2) Mengimplementasikan penggunaan Pupuk Organi Cair (POC) sebagai alternatif pengganti pupuk $\mathrm{AB}$ Mix pada pertanian hidroponik.

Implementasi pembuatan dan aplikasi POC akan dilakukan dalam bentuk sosialisasi, pelatihan, dan praktek. Sosialisasi dan pelatihan akan dilakukan dalam bentuk penyampaian materi (teori). Peserta sosialisasi dan pelatihan berasal dari anggota KKM BON Farm Narmada. Kelompok beranggotakan 15 orang yang berasal dari berbagai kalangan dan umur. Penyampaian materi dilakukan dalam bentuk klasikal. Materi yang akan disampaikan terdiri dari (1) memperkenalkan pertanian hidroponik, (2) menyampaikan teknik bertani menggunakan sistem hidroponik, (3) melakukan uji coba penerapan POC sebagai alternatif pengganti pupuk $\mathrm{AB}$ Mix pada pertanian hidroponik.

\section{Hasil dan Pembahasan}

\section{Sosialisasi Teknik Bertani Sistem Hidoponik}

Kegiatan sosialisasi terkait dengan teknik bertani sistem hidroponik dan aplikasi POC sebagai alternatif pengganti pupuk AB Mix pada pertanian sistem hidroponik dilakukan pada pagi sampai sore hari ( 0800 - 16.00 WITA). Kegiatan ini dilakukan dengan metode klasikal yaitu dengan penyampaian materi mengenai: (1) teknik bertani sistem hidroponik, (2) Pembuatan Pupuk Organik Cair (POC), (3) Pengunaan POC sebagai alternatif pengganti pupuk $\mathrm{AB}$ Mix pada pertanian hidroponik.

Penyampaian materi ini disampaikan oleh ketua pelaksana kegiatan pengabdian. Penyampaian materi ini bertujuan untuk meningkatkan pemahaman anggota KPM terkait dengan pertanian sistem hidroponik, pembuatan POC dan aplikasinya sebagai alternatif pengganti pupuk $\mathrm{AB}$ Mix pada pertanian hidroponik. Setelah materi selesai disampaikan, tim pengabdian dan anggota tim KPM BON Farm Narmada melakukan diskusi melalui sesi tanya jawab (Gambar 1). 
Ilhamdi et al, Jurnal Pengabdian Masyarakat Sains Indonesia 2020, 2 (1):40-44 DOI : https://doi.org/10.29303/ipmsi.v2i1.20

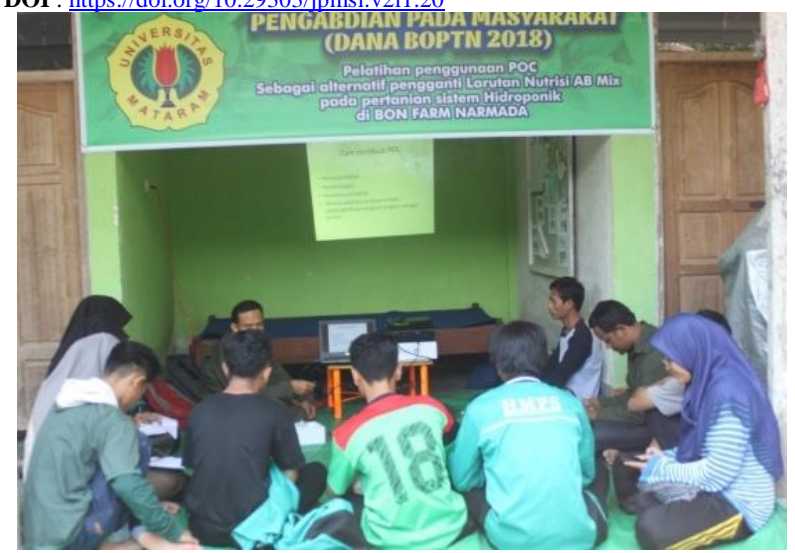

Gambar 1. Sosialisasi teknik bertani sistem Hidroponik

2. Pelatihan Pembuatan Pupuk Organik Cair (POC)

Pelatihan pembuatan Pupuk Organi Cair (POC) merupakan realisasi dari kegiatan sosialisasi. Pelatihan ini dilakukan setelah penyampaian materi oleh tim pengabdian. Pelatihan ini diikuti oleh semua anggota KPM yang dibimbing oleh tim pengabdian. Pelatihan ini dimulai dari persiapan alat dan bahan, proses pembuatan, dan pengemasan.

Tahap pertama dari pelatihan ini adalah penyiapan alat dan bahan yang digunakan untuk pembuatan Pupuk Organik Cair (POC). Alat yang dibutuhkan untuk pembuatan POC adalah ember, pisau untuk memotong dan pengaduk. Sedangkan bahan baku yang dibutuhkan adalah limbah rumah tangga (sayur, buah, dll), kotoran hewan, urin hewan, air cucian beras, gula pasir/molase, sabut kelapa, serbuk gergaji, dan mikroba pengurai/starter EM-4.

Tahap selanjutnya adalah proses pembuatan atau pencampuran bahan baku POC. Pemotongan bahan perlu dilakukan untuk memperkecil ukuran bahan baku agar mudah terdekomposisi oleh bakteri pengurai. Selanjutnya, mencampur semua bahan baku kemudian dimasukkan ke dalam ember penampung dan menambahkan EM-4 yang telah dicampur dengan air secukupnya. Sebagai makanan mikroba pengurai tambahkan air gula/molase kedalam campuran tersebut. Setelah semua bahan tercampur rata, langkah selanjutnya adalah menutup rapat ember dan didiamkan selama 10 hari.

Setelah didiamkan selama 10 hari, langkah terakhir adalah pengemasan Pupuk Organik Cair (POC) ke dalam botol plastik. Campuran bahan POC yang sudah matang/siap pakai akan beraroma alami fermentasi/tape. Larutan tersebut kemudian disaring menggunakan penyaring untuk mendapatkan larutan yang bebas dari padatan
e-ISSN : 2715-2537

p-ISSN : 2715-2545

bahan baku. Larutan POC yang sudah dikemas dalam botol siap diaplikasikan sebagai alternatif pengganti $A B$ Mix pada pertanian sistem hidroponik.

3. Pelatihan Penggunaan Pupuk Organik Cair $(P O C)$ sebagai Alternatif Pengganti pupuk $A B$ Mix pada pertanian hidroponik

Pupuk Organik Cair (POC) merupakan teknologi yang memanfaatkan biokatalisator seperti Effective Microorganism 4 (EM-4). Effective Microorganism(EM4) adalah sejenis bakteri yang dibuat untuk membantu dalam pembusukan sampah organik sehingga dapat dimanfaatkan dalam prosespengkomposan.Kandungan EM terdiri dari bakteri fotosintetik, bakteri asam laktat,actinomicetes, ragi dan bakteri fermentasi (Dewi \&Dewi, 2014). Larutan EM-4 bisa dengan mudah didapatkan di toko pertanian dan sudah terpartisi menjadi bebrapa jenis sesuai penggunaannya (EM-4 Pertanian, EM-4 Peternakan, EM-4 perikanan).

Pelatihan diawali dengan simulasi penggunaan pupuk organik cair (POC) sebagai alternatif pengganti pupuk $\mathrm{AB}$ Mix pada pertanian hidroponik. Penjelasan mengenai teori dasar tentang teknologi EM-4 kemudian dilanjutkan dengan teknis pengaplikasian pada pertanian hidroponik. Tim pengabdian memberikan pengarahan dan memberikan kesempatan kepada anggota KPM BON Farm untuk berpartisipasi melakukan setiap tahapan pelatihan (Gambar 6.3). Konsentrasi yang digunakan pada aplikasi POC untuk pertanian hidroponik mengacu pada penelitian yang dilakukan oleh Hamli, dkk. (2015). Untuk mendapatkan hasil pertumbuhan yang optimal pada tanaman hidroponik digunakan perbandingan $10 \mathrm{ml}$ POC untuk 1 Liter air.

\section{Praktek Aplikasi Pupuk Organik Cair (POC) pada Tanaman Hidroponik}

Praktek aplikasi POC sebagai alternatif pengganti pupuk $A B$ Mix pada pertanian hidroponik dilakukan setelah kegiatan sosialisasi dan pelatihan. Selama melakukan kegiatan praktek ini, tim pengabdian melakukan kegiatan pendampingan sampai dengan panen sayuran hidroponik. Praktek diawali dengan kegiatan pembuatan media tanam hidroponik termasuk didalamnya adalah penyiapan rook wall sebagai media tanam dan kotak sterofoam serta rangkaian pipa PVC sebagai penampung air nutrisi pada sistem NFT (Gambar 2). 
Ilhamdi et al, Jurnal Pengabdian Masyarakat Sains Indonesia 2020, 2 (1):40-44 DOI : https://doi.org/10.29303/ipmsi.v2i1.20
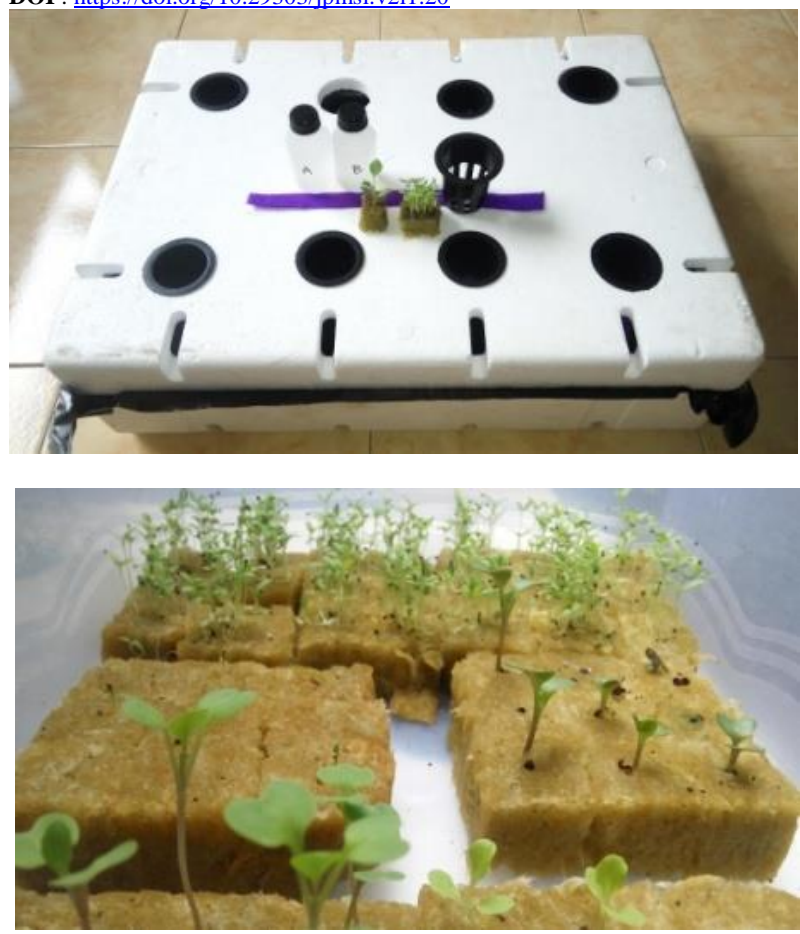

Gambar 2. Media tanam hidroponik

Setelah media tanam disiapkan, langkah selanjutnya adalah melakukan penyemaian benih dengan mengisi rock wall yang sudah dipotong dadu dengan benih sayuran. Pada kegiatan pengabdian ini digunakan benih pakcoy. Selain banyak digemari oleh ibu rumah tangga, sayuran ini juga memiliki beragam manfaat bagi kesehatan. Usia panen sayuran ini tergolong singkat yaitu sekitar 30 hari. Selain itu, sayuran ini juga memiliki harga yang cukup tinggi bagi komunitas pecinta sayuran organik/vegetarian.

Setelah benih berumur 2 minggu/ sudah tumbuh daun sejatinya, sudah saatnya untuk dipindah ke media tanam hidroponik. Sistem tanam yang digunakan adalah sistem sumbu (Wick) dan sistem NFT. Sistem sumbu tidak memungkinkan untuk mengalirkan air sehingga membutuhkan bantuan aerator atau pengadukan yang rutin untuk suplay udara dan melarutkan nutrisi yang mengendap. Sedangkan sistem NFT memungkinkan untuk mengalirkan air sehingga bisa dipastikan suplay udara dan nutrisi tetap konstan.

Sesuai dengan tujuan dari kegiatan pengabdian ini maka nutrisi $\mathrm{AB}$ Mix yang biasa digunakan oleh petani hidroponik diganti menggunakan nutrisi POC. Pemberian nutrisi berdasarkan hasil penelitian Hamli, dkk (2015) yaitu $10 \mathrm{ml}$ POC untuk 1 Liter air. Pengukuran $\mathrm{pH}$
e-ISSN : 2715-2537

p-ISSN : 2715-2545

dan konsentrasi larutan menggunakan $\mathrm{pH}$ meter dan TDS meter rutin dilakukan. Penambahan nutrisi untuk sistem wick dan NFT dilakukan bila konsentrasi nutrisi pada larutan menurun karena diserap oleh tanaman.

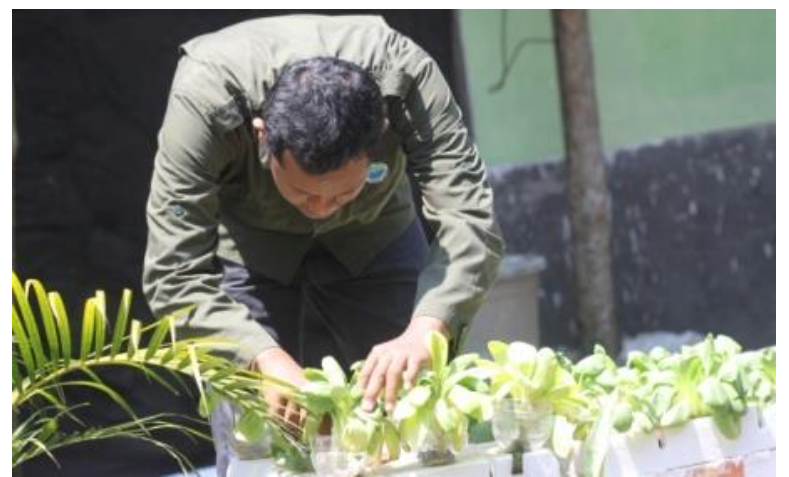

Gambar 3. Panen sayuran hidroponik POC

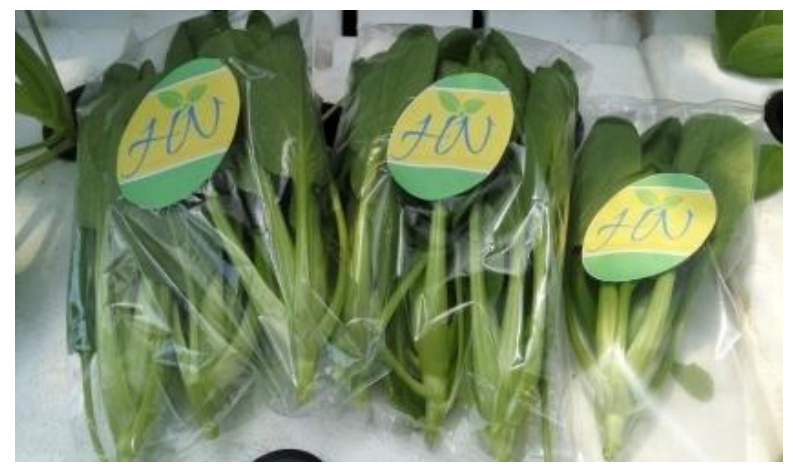

Gambar 4. Penanganan pasca panen sayuran hidroponik POC

Pemanenan dilakukan stelah \pm 50 hari perawatan. Pertumbuhan sayuran yang diberikan nutrisi POC tidak berbeda jauh dengan pertumbuhan sayuran yang diberikan pupuk $A B$ Mix hanya saja waktu panen menjadi sedikit lebih lama. Kelebihan sayuran yang diberikan POC adalah memiliki tekstrur yang lebih renyah dan warna daun yang lebih memikat. Selain itu, bisa dipastikan sayuran yang diproduksi adalah sayuran organik dan baik bagi kesehatan. Pengemasan dilakukan sebaik mungkin dengan plastik agar tetap segar ketika sampai ke konsumen. KPM BON Farm memberikan label "Hidroponik Narmada" pada produk sayur hidroponik yang dihasilkannya.

\section{Kesimpulan}

Kegiatan pengabdian terkait dengan Penggunaan Pupuk Cair Organik (POC) sebagai alternatif pengganti pupuk $\mathrm{AB}$ Mix pada pertanian 
Ilhamdi et al, Jurnal Pengabdian Masyarakat Sains Indonesia 2020, 2 (1):40-44 DOI : https://doi.org/10.29303/ipmsi.v2i1.20

sistem hidroponik ini menghasilkan beberapa hal penting diantaranya ialah :

1. Sosialisasi dan pelatihan pertanian sistem hidroponik dapat meningkatkan pengetahuan anggota KPM BON Farm Narmada tentang teknik pertanian hidroponik terutama dengan sistem NFT.

2. Pelatihan pembuatan POC menambah pengetahuan anggota KPM BON Farm Narmada.

3. Praktik aplikasi POC sebagai pengganti $A B$ Mix meningkatkan keterampilan dan inovasi yang diterapkan oleh BON Farm Narmada dalam memproduksi sayuran hiroponik.

\section{Saran}

Hasil dari kegiatan pengabdian ini menunjukkan bahwa waktu panen yang dibutuhkan dengan aplikasi POC ini relatif lebih lama dibandingkan dengan menggunakan pupuk $A B$ Mix. Oleh karena itu, perlu dilakukan penelitian lebih jauh terutama mengenai variasi bahan yang digunakan dalam pembuatan POC dan unsur tambahan yang dibutuhkan oleh tanaman hidroponik agar tanaman tumbuh dengan optimal dan mempercepat waktu pemanenan.

\section{Ucapan Terima Kasih}

Terima kasih kami ucapkan kepada Rektor Unram melaui dana BOPTN dapat membiayai kegiatan pengabdian ini. Demikian juga kepada kelompok pemuda Narmada yang berpartisipasi aktif dalam kegiatan ini.

\section{Daftar Pustaka}

Fitriyatno, Suparti, Sofyan, A. 2012. Uji Pupuk Organik Cair dari Limbah Pasar terhadap Pertumbuhan Tanaman Selada (Lactuca sativa) dengan Media Hidroponik. Prosiding Seminar Nasional IX Pendidikan Biologi FKIP UNS, Semarang

Hamli, F., Iskandar M. L., Ramal Y. 2015. Respon Pertumbuhan Tanaman Sawi (Brassica juncea 1.) Secara Hidroponik terhadap Komposisi Media Tanam dan Konsentrasi Pupuk Organik Cair. Agrotekbis 3 (3) : 290-296
e-ISSN : 2715-2537

p-ISSN : 2715-2545

Krisnawati, D. 2014. Pengaruh Aerasi Terhadap Pertumbuhan Tanaman baby Kailan (Brasicca oleraceae Var. Achepala) Pada Teknologi Hidroponik Sistem Terapung di Dalam dan diuar Grenhous. Skripsi. Jurusan Teknik Pertanian. Fakultas Pertanian. Universitas Lampung

Perwitasari B., Tripatmasari M. dan Wasonowati C. 2012. Pengaruh Media Tanam dan Nutrisi Terhadap Pertumbuhan dan hasil Tanaman sawi (Brassica juncea L.) Dengan Sistem Hidroponik. Agrovigor Vol 5(1): $14-25$

Rest, H.M. 1983. Hidroponics food production. Woodbridge Press Publishing Company. Santa Barbara dan Calipornia. 